\title{
Kindergarten' optics
}

\section{Manuel M. Costa, Júlia Campos, Madalena Lira, Sandra Franco}

Manuel F. M. Costa, Júlia Campos, Madalena Lira, Sandra Franco, "Kindergarten' optics," Proc. SPIE 9666, 11th Education and Training in Optics and Photonics Conference, 966605 (5 June 2009); doi: 10.1117/12.2207953

SPIE Event: Eleventh International Topical Meeting on Education and Training in Optics and Photonics, 2009, St. Asaph, United Kingdom 


\title{
KINDERGARTEN' OPTICS
}

\author{
Manuel F. M. Costa, Júlia Campos, Madalena Lira, Sandra Franco \\ Universidade do Minho, Departamento de Física \\ Tel. +351 253 604070; Fax. +351253678981 \\ e-mail: mfcosta@fisica.uminho.pt \\ 4710-057 BRAGA \\ PORTUGAL
}

\begin{abstract}
The introduction to our school' students of the wonders of light and optics and its understanding can and should be made as extensively as possible. As soon as at kindergarten level!

A hands-on approach leading the students to observe experiment and discover themselves in a critical committed and active way the different aspects of light and optics should be employed at all school levels and must be the main driving pedagogical practice of all learning process of science and technology.

In this communication we present a series of experiments and support material designed in this hands-on perspective to be used to introduce the study of optics to kindergarten and early basic school students. A critical evaluation of the first results of the application of these material with students aged 4 to 10 years will be presented.
\end{abstract}

\section{Introduction}

Young children are always eager to learn to see new things but also to know and to understand the world that surround them.

With reduced "pre-knowledge" usually, there are no previously acquired misconceptions or even prejudices. Also there no exams to study for... "just" the innate survival need to know. However, since they were born a permanent learning process take place at an extremely fast pace.

Eleventh International Topical Meeting on Education and Training in Optics and

Photonics, edited by K. Alan Shore, Deb Kane, Proc. of SPIE Vol. 9666, 966605

(C) 2009 SPIE, OSA, IEEE, ICO · doi: 10.1117/12.2207953 
Children learn from the environment from what they feel from what they live. As we could see when contacting children in this age range, 4 to 10 years old, a constant reference to their every day life and previous experiences is made.

Hands-on [1,2 ]activities are fundamental and the "natural" approach for these young students.

The first concern of the educator should be, with this clear perspective in mind, to show... or better... to let the children to "see", to observe, to confront themselves with new objects processes and situations.

Time is fundamental and should be generously given to the young students. Of course some "pressure" can be useful... in due time... respecting each ones pace. From early kindergarten years the children should "learn", should be lead to work in group to interact and cooperate with peers towards a common goal.

Care however should be taken by the educator in order to ensure that each student will have, in these group activities, the needed time to establish their own "knowledge" while guarantying that no children, apparently "faster", feels uncomfortable "waiting" for the others. No sense of superiority, or inferiority, or even of condescendence, in this competition process that always appears in these situations at these ages, should be rewarded. Yet fundamental it is that the each child understands, step by step, the importance of "cooperation", of listening the other letting the others to know of our findings, helping and accepting to be helped in the sake of a common goal.

How to do that?... a Portuguese popular saying (certainly with equivalents throughout the word!) "words are silver, silence is gold"... be patient give time to the students, and to your self..., open widely your eyes and lead the way smoothly affirmatively and discreetly. Words might be made of silver but it is fundamental that the child is able to verbalise coherently their feelings their findings their opinions. Hands-on should be complemented with a constructivist [3] approach and others like construcionism [4] and conceptual learning [5].

"Always" hands-on but not blind/mechanically... “... do this and then that and that and..." Learning is discovering... by the student... himself... actively and reflexively.

\section{Light and optics at the kindergarten}

Being related to one of our main senses, being the eyes a major gateway to the world that surround us, light related phenomena are rather appealing to young children [6]. Young students readily realize the importance of seeing and the role of their eyes and of light sources. They are 
particularly attracted to the colour phenomena, to reflection and transparency, to shade and changes in luminosity...

Below we present a set of simple experiments that we designed for 4 to 10 years old students and that may serve as basis for teachers and educators to use in their classrooms and in informal activities [7].

We divided the experiments in three parts. A first one intends to introduce the role of the eye and ... we need light to see objects. At the second part we intend to show using a simple model how the eye works. Finally the third part deals with light and colours and is by the most attractive one for our young scientists.

\section{Light and optics experiments in the kindergarten and elementary schools}

\subsection{Part 1.}

The main concept behind this first set of experiments was: we need light to see objects.

The experiments were design to show that:

- We see an object because the light from the object enters the eye through the pupil. Constriction of the pupil limits the amount of light entering the eye, and dilating of the pupil allows more light to enter the eye. So, in bright light, the pupil constricts, and in darkness, the pupil dilates. (Experiment 1)

- $\quad$ There are objects that emit light (ie, light sources) and others that reflect light. (Experiment 2)

- $\quad$ Light is reflected from the surface of objects. Dark objects reflect little light while white objects reflect more light (Experiments 3 and 4. Figure 1.).

Experiment $n^{\circ}$. 1. Pupil observation

Background: The light enters the eye through the pupil. The pupil has to adapt to different light intensities.

Method: The children are divided into groups of 2 or 3 . The room light is dimmed and penlights are distributed to each group. It is asked to one of the children to illuminate his/her eyes while the others observe the pupil closing down. 


\section{Experiment $n^{\circ} .2$ Luminous and non-luminous objects}

Background: There are objects that emit light and others that reflect light.

Method: The room is dimmed. Light emitting objects (of different types) and non-luminous objects are available and are shown. The similarities and differences between the various types of light sources and objects are discussed.

\section{Experiment $n^{\circ}$. 3. Brighter and darker objects}

Background: The light is reflected from the surface of the objects. The dark objects reflect little light while white objects reflect more light.

Method: Several objects of different colours are placed in a black box with the front face open. The room light is dimmed leaving only a small lamp behind the box. The position of the lamp is gradually changed to allow some light to reach the objects inside the box. As the inside of the box becomes more illuminated the darker objects become progressively more visible.

Experiment $n^{\circ}$. 4. Light reflected by objects

Background: The light is reflected from the surface of objects. The dark objects reflect little light while white objects reflect more light.

Method: In a very dark room, each child place him self in front of a mirror. One hand holds a penlight on one side of the face in order to lighten the nose. The child is asked to observe his/her face in the mirror (figure 1.).

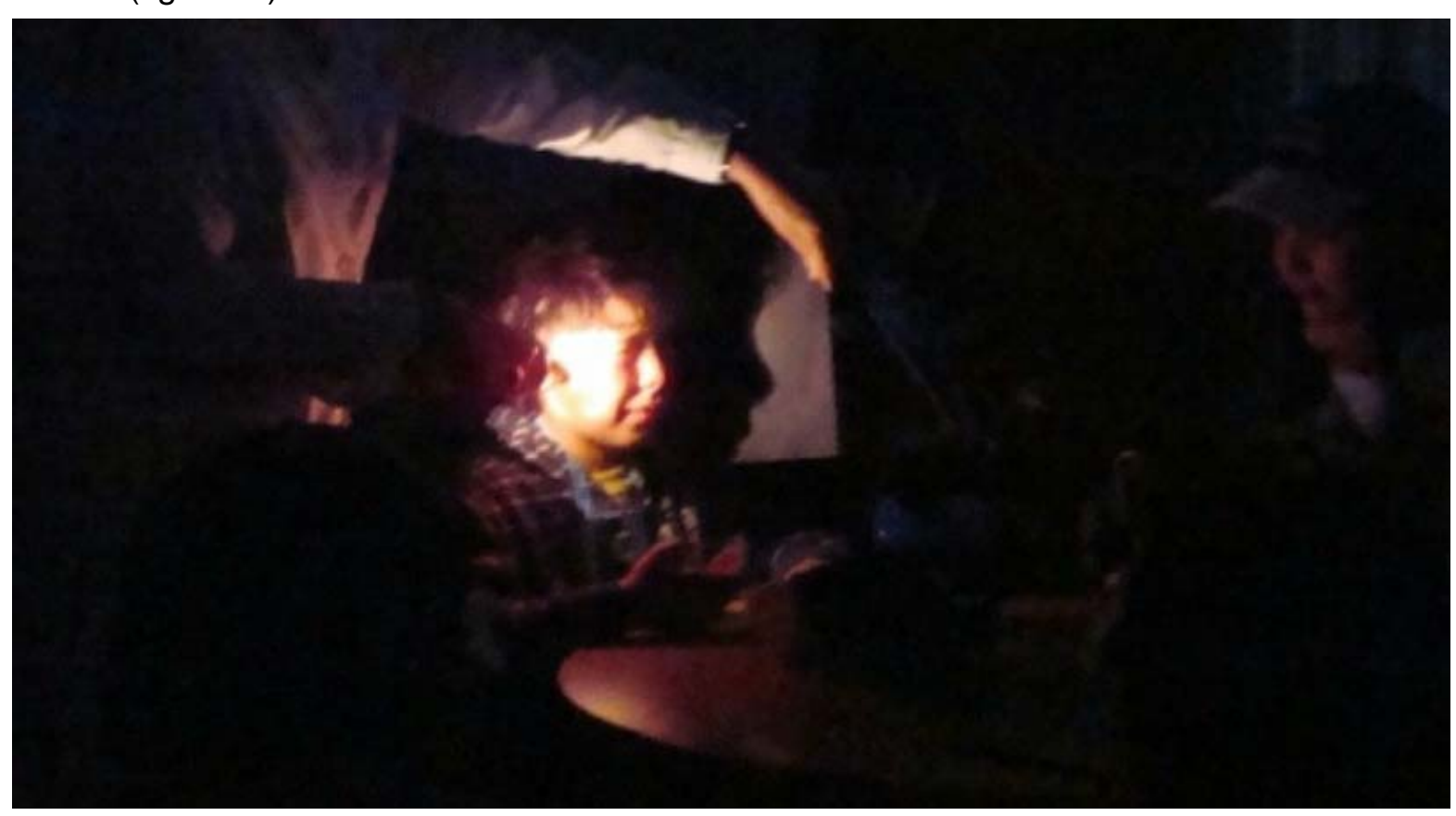

Figure 1 - The light reflected by the objects' experiment. 
The experiment is repeated by holding a white cardboard with the other hand, parallel to the side not illuminated. The procedure is then repeated by replacing the white cardboard by a black one and then by cardboards of different colours. Finally the student replace the card a by a second mirror. Children record and discuss what they saw happening on the non-illuminated part of their face when using the different colours or the second mirror.

\subsection{Part 2.}

The main goal of these set of experiments is to illustrate how our eye work

The experiments were design to show that:

- How the image of an object is focused on the retina. (Experiment 1)

- What is accommodation. (Experiment 2)

- $\quad$ Seeing "bad"... What is myopia and hyperopia. (Experiment 3)

These set of experiments were performed with a model of the human eye (figure 2.).

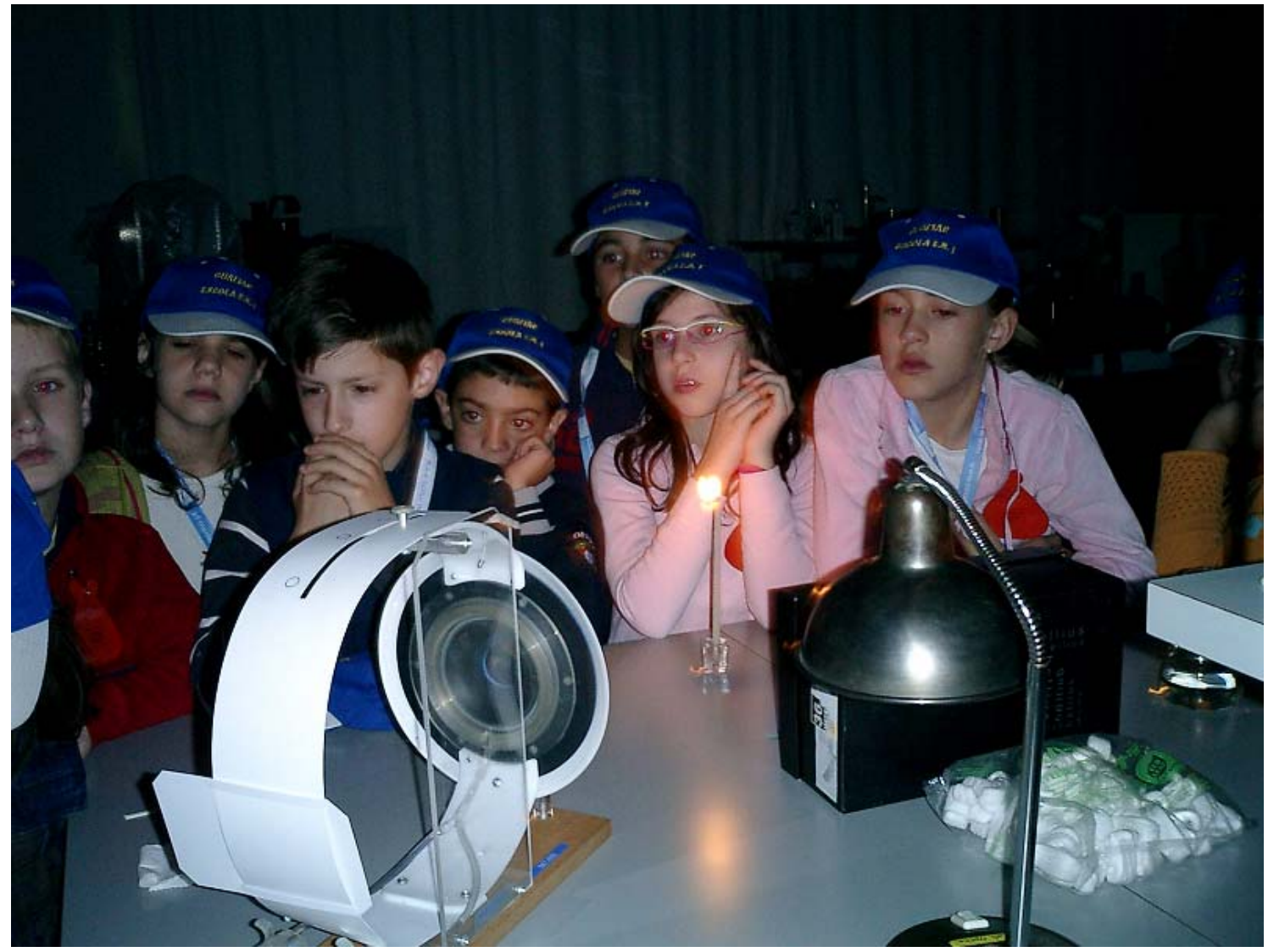

Figure 2- How the eye works experiments 
Experiment $\mathrm{n}^{\circ}$ 1. Using a bright light source (a candle may be used under teachers supervision), images can be focused on the model's retina simulating the human eye imaging mechanism.

Experiment $n^{\circ} 2$. To demonstrate the accommodation the lens can turn thicker or flatter to focus the image on the retina. The lens is a chamber constructed of optically clear silicone elastomer connected by tubing to a water-filled syringe. Water forced into the lens increases its thickness and curvature; withdrawal flattens the profile of the lens, changing its focus.

Experiment $n^{\circ} 3$. The eye model can simulate refractive problems (that some children may suffer from). Myopia and hyperopia can be simulated by changing the eyes' shape (length). It is also possible to use corrective lenses. Whenever there is a child using spectacles it may be used to illustrate the correction effect (if the teacher/educator is not confident enough with the process, is probably better to skip this step unless some students points it out (which often happens... fortunately...).

\subsection{Part 3.}

Colour is the main concept addressed at this last set of experiments.

The experiments were design to show that:

- It is easy to separate white light' colours (Experiments 1 and 2).

- $\quad$ We get white light by adding green, red and blue light (Experiment 3).

- $\quad$ Getting yellow, magenta or cyan colours (Experiment 4).

- $\quad$ Object' colour depends on the light reflected from them (Experiment 5).

Experiment $n^{\circ}$. 1. White light decomposition 1.

Background: White light is "composed" of all the colours in the rainbow.

Method: Using a bright white light source (placing a slit in front may help), a beam of white light is projected onto a white smooth surface (target). With a diffraction grating and, or, a prism, the light is decomposed, projecting the light spectrum on the target (it may not be easy to get all colours clearly visible... children must learn to be patient and resilient). Colour filters are placed in front the beam and, as always..., discussed. 


\section{Experiment $n^{\circ}$. 2. White light decomposition 2.}

Background: White light is "composed" of all the colours in the rainbow.

Method: CDs are distributed to the children. They observe the decomposition of sunlight (the ceiling lamp or even the light emitted by a computer screen) into the rainbow. The experiment is then repeated with a pocket spectrometer.

Experiment $n^{\circ}$. 3. and 4. Mixing light with different colours.

Background: Adding green red and blue light allows us to get white light.

Method: Three light sources are used - one red, one green and one blue (simple flashlights with colour filter - the teacher must check ahead how red is the red, how green is the green...). The three beams are directed to one point of a smooth, not polished, white wall or board.

Children are also asked to make shadows with their hands (figure 3.) and notice all the colours observed. The experiment is repeated with only two lamps connected at a time. The concept of subtractive colour missing may also be addressed.

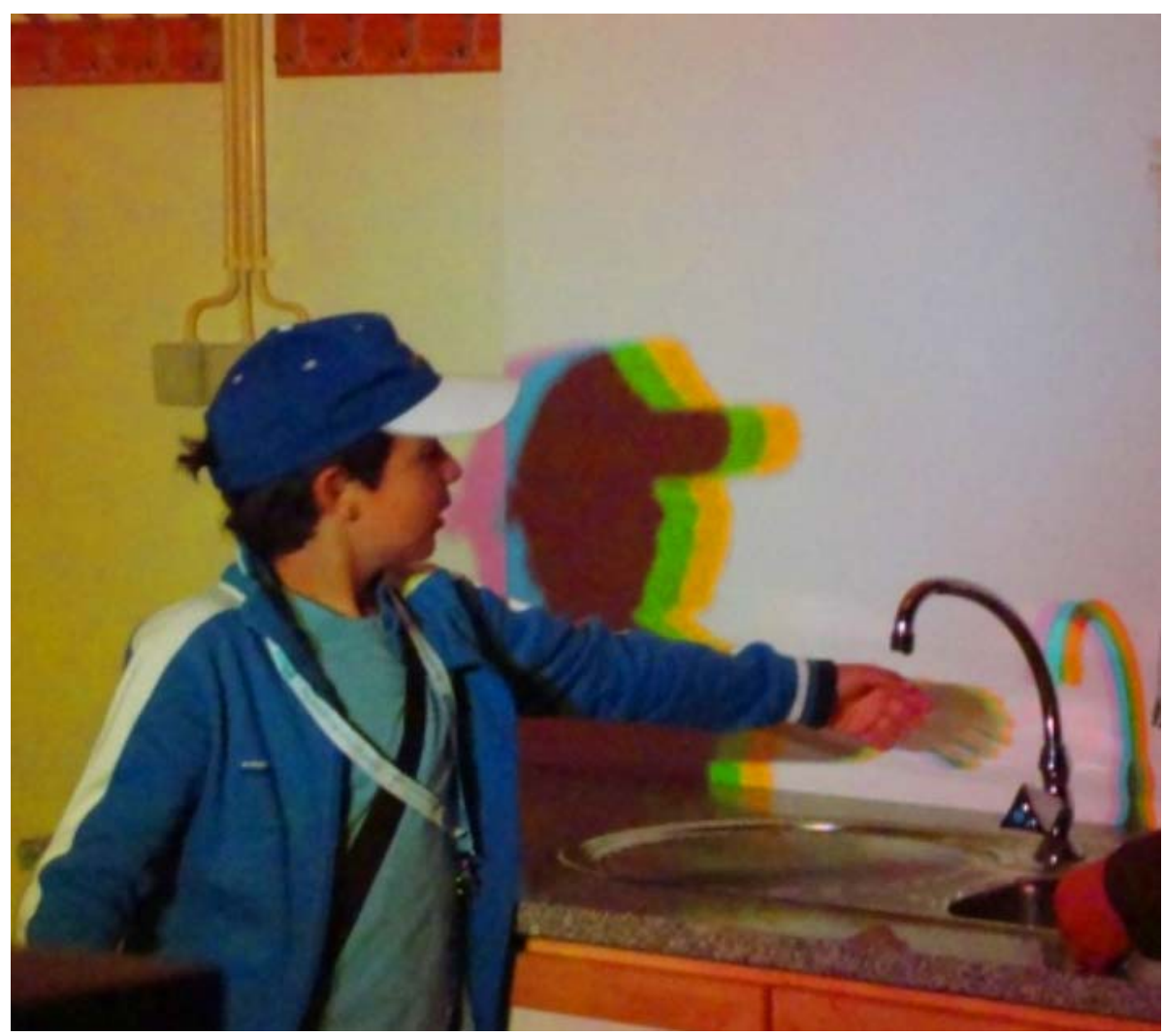

Figure 3 - Colour shadows. 


\section{Experiment $n^{\circ} .5$.}

Background: The colour of objects depends on the light reflected from them.

Method: This experiment is done using the same light sources used before and at the same positions. Several cardboard pictures of different colours (the cardboard should not be shiny) are placed on a black board (figure 3). Those colour cards are illuminated with one of the lamps and repeated with each one of the other lamps and combinations of them. At the end the three lamps are switched on. (Especially for these two last experiments it is necessary to dim significantly room lights).

\section{Brief discussion and conclusion}

We decided to invite a group of elementary school students (ages 6 to 10 years old) to the university in order to perform these sets of experiments.

The activity was rather successful pleasing to students and teachers. Although stating their clear preference that the colour experiments were the most pleasant ones, the results were in general very positive, during the execution itself and in the follow-up activities undertaken back at the school.

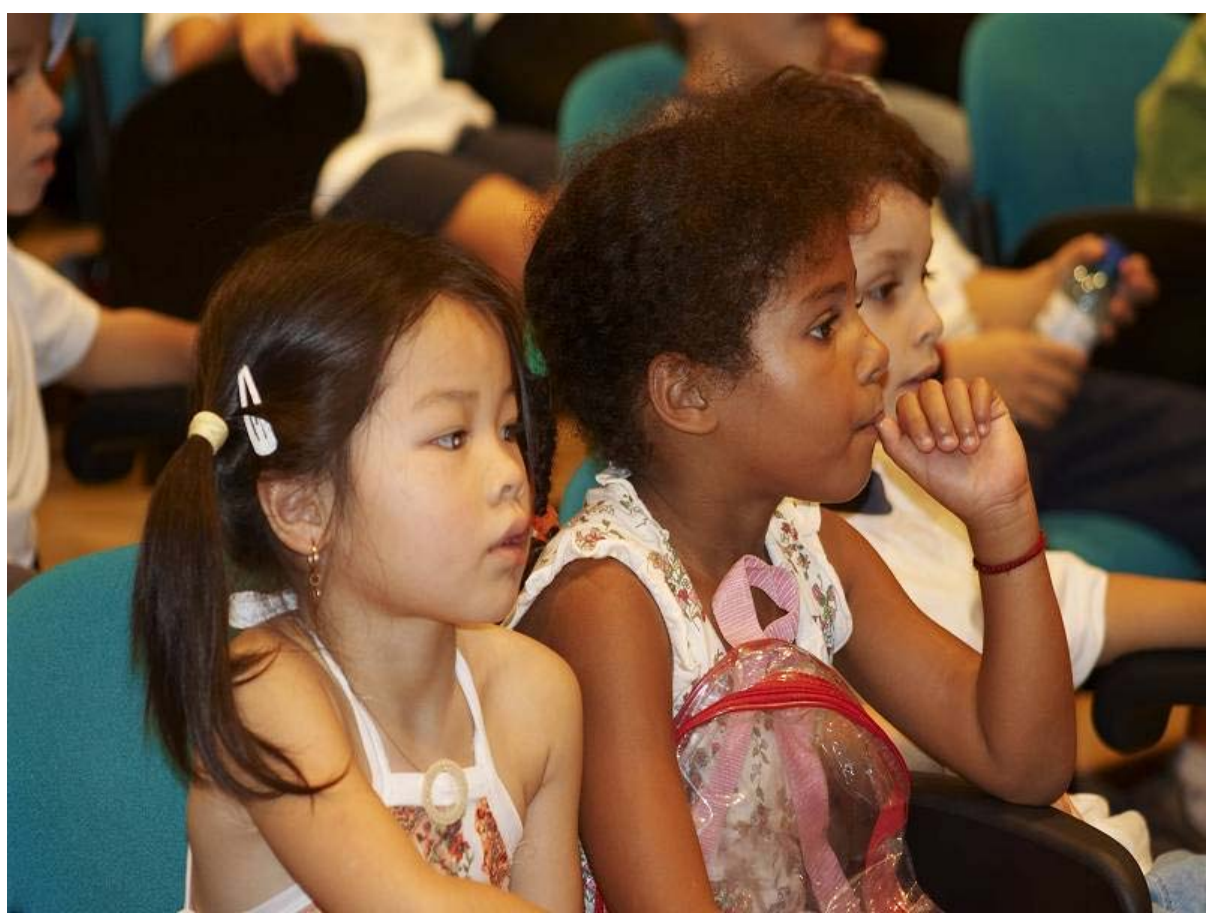

Figure 4. Demonstrations and visits to museums and science fairs might be very useful if a follow up work is prepared by the educator and conducted in classroom context.

Follow-up, in fact, should always be considered very important. These non-formal or informal activities (visits to labs, museums, science fairs or lectures, figure 4.) should always be followed of work sessions in the classroom exploring the motivation achieved and developing and or 
strengthening the knowledge transmitted/acquired. At the end of our activity a series of enquiries and quizzes were delivered to the teachers and asked to be returned for analysis and statistical treatment. Furthermore we distributed to the students material and short guidelines to build, on their own, a kaleidoscope and a simple pinhole camera (a muffin aluminum cup, a rubber band and a soft translucent paper sheet is enough...).

Being clear for us that the students easily and correctly are able to understand the importance of the eye in the process of seeing, we decided to explore a little bit the vision process. We used a simple model of the eye with a pupil, a rubber lens that could be inflated using a water syringe and a retina like displaceable target, which can be easily built. We expected the students to have difficulties in understanding the process or even accepting it ... we were inside the eye...! In fact only older students, 9 to 10 years old, were able to deal with it.

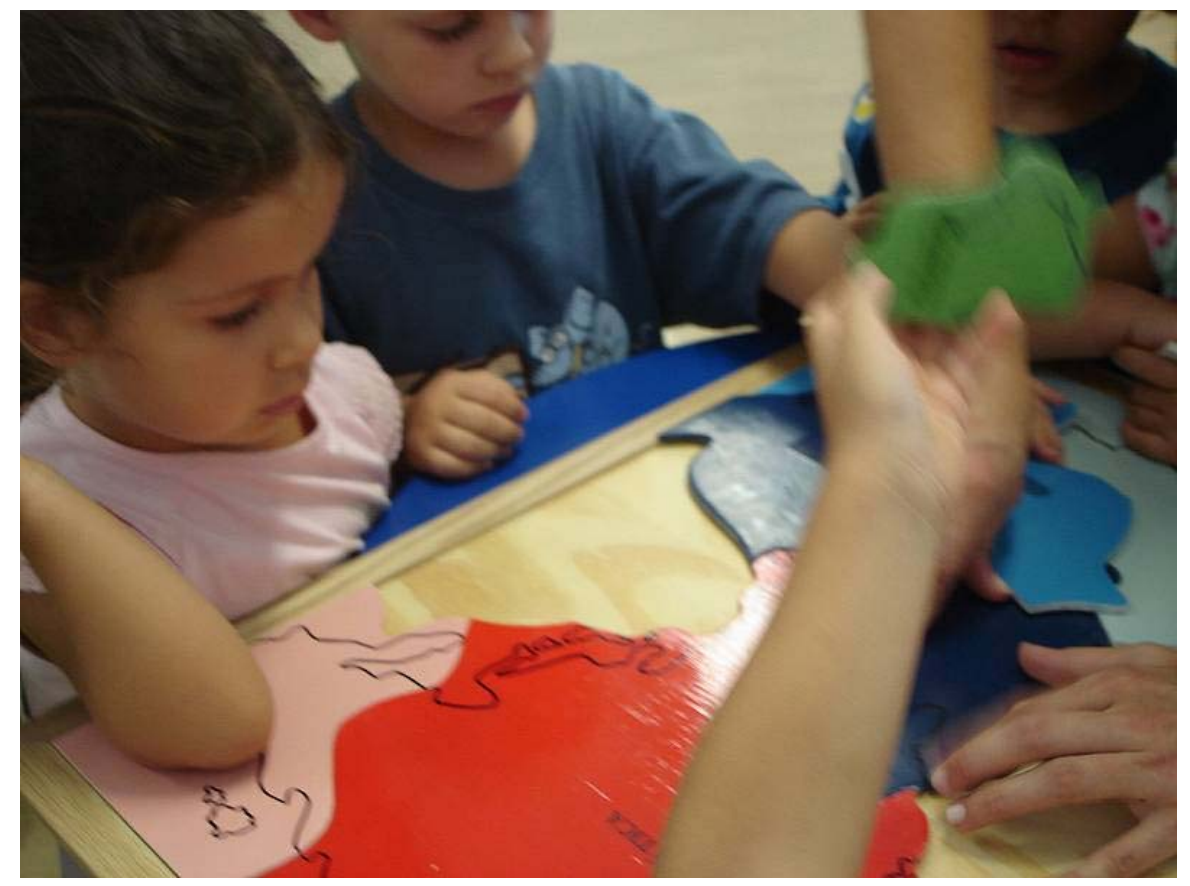

Figure 5. Shapes and colours.

The age span covered, 4 to 10 years old, is rather large (especially as dealing with children). One must carefully cope with the differences... being flexible but always observing child's' reactions.

From very early ages young children are strongly attracted to colours, in particular to bright principal colours, are fascinated by the wonders of colour mixing and they seem more attracted to additive mixing opposite to what happens with school students that before being presented to the issue had previous experience in mixing ink for paintings (the subtractive process). The hands-on manipulation of colour cards (especially if being part of games) is particularly effective (figure 5.). 
In general the basic concept covered by these experiments (specially part 1 and 3) are readily understood by the young children that immediately after realizing the concept present a series of examples related to their own experience (... when electricity failed and lights went off I was afraid my mama leave me alone in the dinner table...). This type of reaction happens quite often (normally older students are more "careful" expressing their feelings and ideas and restrain them selves) and is a good indication that some level of understanding of the concept was achieved.

\section{References}

1. "Hands-on Science"; Costa MFM; Selected Papers on Hands-on Science (ISBN 978-989-953362-2); Costa MF, Dorrío BV, Michaelides P and Divjak S (Eds.); Associação Hands-on Science Network, Portugal; pp. 1-13 (2008).

2. Gatt S. (ed.), (2006) Primary Science Teachers Handbook, European Commission Comenius 3 project: Hands on Science Network, Malta.

3. "Constructivism - An effective Theory of Learning"; Gatt S; Constructivist teaching in Primary School Social Studies, Mathematics, Science, ICT, Design and Technology; Gatt S and Vella Y (Eds.), Agenda Publishers, Malta (2003).

4. "A Study of Educational Robotics in Elementary Schools"; Ribeiro C, Coutinho C, Costa MFM and Rocha M; Selected Papers on Hands-on Science (ISBN 978-989-95336-2-2); Costa MF, Dorrío BV, Michaelides P and Divjak S (Eds.); Associação Hands-on Science Network, Portugal; pp. 580-595 (2008).

5. "Teaching Physics Modelling with Graphic Simulations Tools"; Zamarro JM, Molina GJ and Núñez MJ; Selected Papers on Hands-on Science (ISBN 978-989-95336-2-2); Costa MF, Dorrío BV, Michaelides P and Divjak S (Eds.); Associação Hands-on Science Network, Portugal; pp. 6973 (2008).

6. Learning Optics at Basic Schools by Experimentation"; Costa MFM; Selected Papers on Handson Science (ISBN 978-989-95336-2-2); Costa MF, Dorrío BV, Michaelides P and Divjak S (Eds.); Associação Hands-on Science Network, Portugal; pp. 25-28 (2008).

7. Manuel F.M. Costa, Hands-on Introduction to Optics / Introdução à Óptica (bilingual edition), Hands-on Science Network, ISBN 989950952 3, September 2006. 